\title{
HIPPOTHERAPY AS AN ALTERNATIVE METHOD OF IMPROVING THE PRAXIS FUNCTION IN CHILDREN WITH MULTIPLE DISORDERS
}

\author{
Diyana Georgieva ${ }^{1}$, Veselina Ivanova ${ }^{2}$
}

\begin{abstract}
In recent years hippotherapy has emerged as one of the most commonly used alternative methods for the development of praxis functions in children with multiple disorders. The research focus is on the study of basic parameters of motor function in children with multiple disorders and the assessment of the horseback riding effects on the development of praxis of individuals in the category observed. A research battery consisting of three standardized tests: the Single-Leg Balance Test, a test and a scale for assignment the posture during a ride (The Posture Assessment Bertotti Scale) and a Test for the Estimation of Horse-riding Dependence on Danzinger, covering three application stages: diagnostic, intermediate, and control. A Student's one-sample T-test was used to process the results obtained. Participants in the experimental group, aged between 7 and 15, showed results which are undoubtedly evidence of improvement in their praxis functions.
\end{abstract}

UDC Classification: 159.9, DOI: 10.12955/cbup.v7.1394

Keywords: hippotherapy, praxis, children with multiple disorders

\section{Introduction}

One of the main priorities of contemporary educational systems in Bulgaria and around the world is the problem of providing therapy and education to children with complicated and complex disorders of different type, nature and extend. At the same time, there is an alarming fact about the increase in the number of these children. There is a particularly high percentage of children with clinical symptoms, that indicate a malfunction of the complex motor programs, that determine mastery of motor skills, habits, and handiness. A natural consequence is the lack of pleasure and joy in their overall functioning. Therefore, one of the key tasks in the process of special pedagogical intervention of the presented heterogeneous group of children consists of the application of well-founded therapeutic approaches and strategies to develop their motor potential, which would provide greater autonomy, emotional balance and comfort.

For many years, physical rehabilitation has taken the lead in the complex rehabilitation process of children with multiple disorders as a natural biological method for the development of the praxis function. It includes healing exercises/gymnastics (passive exercises, reflex exercises, active exercises, water exercises), manual therapy (massage), and the specialized methodologies of Bobath, Kabat, and Voita.

In recent years hippotherapy has become an effective model for the development of the motor sphere. The uniqueness of the alternative method is due to the fact that as a result of rhythmic alternation of motor and sensory stimuli, directed to the rehabilitated person through the close contact with a horse, a stable holistic effect is achieved. The diversity of biomechanical influences combined with an emotional component, achieved during the hippotherapeutic sessions, cannot be attained through application of traditional means of improvement of the praxis function.

\section{Literature Review}

A group of children, which cannot be attributed to the existing categories of disorders due to the combination of different nosological units of primary nature, stand out in the special pedagogical area. Multiple disorders are a particular holistic phenomenon which characterizes a specific situation in a child's development. A unified definition towards the variability of the possessed disabilities is difficult. In 1974, the US Department of Education formulated one of the first and internationally recognized definitions of children with multiple disorders, according to which the depth of their medical, sensory, mental, motor and emotional problems implies a range of medical, physical and educational care beyond the scope of traditional support.

At the heart of contemporary views and theories on the development of the mind of a child with disorders are the objective laws formulated by Vygotsky (1998) with a concept structure of atypical development. According to the author's point of view, the existence of destruction in an functional system does not cause an isolated dropping of that function, but leads to a series of interrelated deviations which determine in their collectiveness the overall picture of atypical development. The

\footnotetext{
${ }^{1}$ Trakia University, Faculty of Education, Stara Zagora, Bulgaria, paskaldi1929@abv.bg

2 Trakia University, Faculty of Education, Stara Zagora, Bulgaria, v_g_chipeva@abv.bg
} 
complexity of the structure of "abnormal" development occurs in the presence of a primary defect, provoked by a biological factor, and secondary disorders, arising as a consequence of the primary. Preserved functions which can serve as a basis for a good prognosis and a successful therapy are always present in the structure of dysontogenesis. In his concept, Vygotsky (1998) pays special attention to the constellation primary - and secondary disorders which determine the peculiar functioning of the mind. A systematic approach to a comprehensive and expanded study of impaired mental development implies not only disclosure, reporting and determination of the proportion of impaired functions, but also a complex and detailed analysis of the reserved structures and their functional capacity, serving as a foundation for the determination of the content and organization of the development training and therapy.

One of the emerging strategic directions in contemporary Bulgarian special pedagogy is the creation of a unified system of alternative methods and strategies for overall support of children with multiple disorders in their psycho-physical development. One of these methods is hippotherapy. The method of hippotherapy has a sufficiently long history, and is now widespread and recognized worldwide. The term "hippotherapy" is an international term denoting the use of communication with a horse and horse riding as a means of rehabilitation, adaptation and integration of children with atypical development. In this context, researchers are united in their belief that the method is particularly effective for children with complex development disorders and limits in their vital functioning (McCloskey, 2000; Silkwood-Sherer \& Warmbier, 2007).

Significant effect has been reported in children with cerebral palsy, poliomyelitis, early childhood autism, mental retardation of different genesis, Down syndrome, dysfunction of sensory integration, attention deficit hyperactivity disorder, mental, emotional and psychosomatic disorders, behavioral deviations, and multiple sclerosis (Gencheva et al., 2015). Disorders in the praxis function have been observed in all these children, without exceptions.

Praxis includes all voluntary movements, which, after the education and training period, begin to be performed with accuracy and precision. The motor act is a complex system with self-regulation, extensively and intensively implemented, and including a prediction mechanism.

Mobility disorders in children with multiple disorders are manifested to a varying degree. Even in the period of early childhood the development of self-seating, creeping, straightening skills marks a late start. Movements are characterized by delay, clumsiness, and impulsiveness. Their lightness, skillfulness and balance are not among the main characteristics of atypical development. At the same time, the occurrence of pointing gestures, head movements indicating agreement/disagreement, as well as purposeful movements initiating social acts of greeting and farewell, is also delayed. Difficulty in the imitation of movements and gestures of adults is observed, and in many cases the presence of resistance in training in motor skills is noted. Some of the characteristics of facial expression are meager/poor gestures, tension, and in some cases the face lacks expression, devoid of the ability to produce non-linguistic signals of communication.

Hippotherapy has a complex effect on the organism which positively affects the child's physical development. Compared to traditional methods of therapy, it has additional benefits. It is based on the use of the motor function which has not only biological, but also psychological and social significance for man (Scott, 2005). Horse riding contributes to the development of balance and the improvement of coordination of movements. Because of the limited physical activity, the accumulated deficit of afferent impulses is overcome.

According to research data, hippotherapy helps to reduce muscle spasms, increases the range of joint movements, and strengths the muscles of the back, abdomen, and limbs (Whalen \& Casa-Smith, 2012). Hippotherapy generates opportunity for multiple repetition of movements, which creates conditions for the formation and consolidation of the skills. The correct position of the patient's pelvis contributes to being able to adjust it to the individual frequency of a living creature - the horse. In this way the latter becomes a natural generator of motor resonance impulses. These components are related to the automated motor reactions of the human body in three planes - sagittal (statics - dynamics), frontal (displacing the center of gravity), and horizontal (rotation). In the course of hippotherapy there is a natural neuromotor integration of the body image, furthermore pelvis and shoulder mobility improves and muscular tone of the back and shoulders normalizes. Horse riding kinetics is such that 
the "rider" position helps to a considerable extent to eliminate adductor spasms, reduce spasticity, and improve posture retention mechanisms (Snider et al., 2007).

The contact with the horse allows the child to attempt to exercise motivated control over the motor act. This is reflected in the transfer of the skills in social life. Gradually mastering the skills to communicate with the animal, the child gains confidence in his/her abilities and begins to identify his/her own personality. The active participation in the hippotherapy team expands the child's motor and emotional space, becoming a favorable background - necessary for self-recognition and aspiration for cooperation.

The conclusion is that, as an alternative method, hippotherapy creates a unique effect, generally affecting the child therapeutic and developmental situation.

This presentation reveals the necessity for a profound study of the effects of hippotherapy in the improvement of praxis function in children with multiple disorders which emerged as the main objective.

The main goal of the study is to research basic parameters of motor function of children with multiple disorders and to assess the effects of horseback riding on the development of praxis on the individuals in the considered category.

\section{Data and Methodology}

The aims of study were achieved through the following:

- Development of a conceptual framework and terminology for the research;

- Analysis of the literature on the therapeutic effects of horse riding for the improvement of motor function in children with multiple disorders;

- Development of an appropriate methodology for the purpose of the study;

- Selection of the participants in the experimental study;

- Comparison of the achievements of the children in the experimental group before and after the sessions of therapeutic horse riding;

- Analysis of the empirical data from the study and formulation of the conclusions.

The object of the study is the condition of praxis function in children with multiple disorders.

The subject of the experimental study is considered the process of improvement of praxis function by using the resources of therapeutic horse riding.

The experimental study involved 19 children with a complex structure of disorders. Mental retardation was found in all of them. $46 \%$ of the children were found to have autistic spectrum disorders. In 54\% of the cases there are sensory disorders (deafness), locomotory system disorders, genetic disorders (mainly Down syndrome), cerebral palsy. The age range varies from 7 to 15 years.

The experiment covers a 5-month period. Therapeutic sessions (35 in number) are held every week on a pre-established schedule for each specific child. The structure of each therapeutic session contained three parts of treatment: a preparatory part, a main part, and a final part of treatment, with a total duration of 15-20 minutes.

For the purposes of the study a battery of tests was used:

- Equilibrium Stability Test - children maintain balance from an initial position standing on one leg up to 20 seconds with eyes open.

- Bertotti test and posture rating scale during horse riding - the therapist observes the position or symmetry of 5 areas of the child's body: head and neck, shoulders and blades, torso, vertebral column and pelvis. The final rating is formulated by the summation of the rating of each observed part of the body during horse riding. Maximum rating -15 .

- Danzinger horse riding dependence test (Gencheva et al., 2015) - the test consists of crossing a specific route, starting, then overcoming, a slalom stand; obstacles - "barriers"; serpentines; finishing at the start point. The same route and exercises are performed and the degree of dependence is taken into account by the therapist. Ratings ranging from 0 to 8 are placed.

Standardized tests are applied in three stages: an initial stage, an intermediate stage, and a final stage. The results are noted in individual protocols. 
For detection of a statistically significant difference between the arithmetic mean of the three tests, a Student's one-sample t-test was used with a predetermined specific for the scientific study control number - "gold standard". The sample analyzed in the study is of moderate size $(15<\mathrm{N}<30)$ and there are no abnormal observations. In the interpretation for the extent of the effect the coefficient $\mathrm{d}$ is calculated using the following formula where,$A$ " is a constant or the "gold standard", „X ${ }^{-}$" is the arithmetic mean, and ,s" is the standard deviation of the sample.

Formula 1: $d=\frac{\bar{x}-A}{s}$

For the parameter "equilibrium stability", the data are shown in Table 1.

\begin{tabular}{|c|c|c|c|c|c|c|}
\hline \multirow{2}{*}{$\begin{array}{l}\text { One-Sample } \\
\text { Statistics }\end{array}$} & $\mathbf{N}$ & Mean & \multicolumn{2}{|c|}{ Std. Deviation } & \multicolumn{2}{|c|}{ Std. Error Mean } \\
\hline & 19 & 3.42 & \multicolumn{2}{|c|}{3.53} & \multicolumn{2}{|c|}{0.81} \\
\hline \multirow{4}{*}{ One-Sample Test } & \multicolumn{6}{|c|}{ Test Value $=0$} \\
\hline & \multirow[t]{2}{*}{$\mathbf{t}$} & \multirow[t]{2}{*}{ df } & \multirow{2}{*}{$\begin{array}{l}\text { Sig. (2- } \\
\text { tailed) }\end{array}$} & \multirow{2}{*}{$\begin{array}{c}\text { Mean } \\
\text { Difference }\end{array}$} & \multicolumn{2}{|c|}{$\begin{array}{l}\text { 95\% Confidence Interval of the } \\
\text { Difference }\end{array}$} \\
\hline & & & & & Lower & Upper \\
\hline & 4.22 & 18 & 0.001 & 3.42 & 1.72 & 5.12 \\
\hline
\end{tabular}

Source: Authors

Since the value obtained for confidence level $p$ is less than $0.05(\mathrm{p}=0.01)$, it can be concluded that there is a difference between the arithmetic mean $\bar{x}=3.42$ and the control number $0 . \mathrm{H}_{0}$ is rejected and the alternative hypothesis $\mathrm{H}_{1}$ is accepted, according to which the observed difference in the samples is statistically reliable and can be summarized for the generic sets. There is a statistically significant difference between "input" and final measurement.

The magnitude of the effect $(\mathrm{d}=0.97)$ is calculated according to Formula 1 . Because $0.97>|0.80|$ (in Cohen, 1988) the magnitude of the effect is interpreted as much larger than the typical magnitude of the effect of the model on the test parameter. The obtained data lead to the summary that the equilibrium resistance of the experimental subjects is improved tangibly.

The favorable result is due to the rhythmic movements of the horse's back as well as by the habit of getting the correct riding position at the end of the healing course of therapeutic riding.

Table 2 shows the results of the horse riding dependence test.

\begin{tabular}{|c|c|c|c|c|c|c|}
\hline \multirow{2}{*}{$\begin{array}{l}\text { One-Sample } \\
\text { Statistics }\end{array}$} & $\mathbf{N}$ & Mean & \multicolumn{2}{|c|}{ Std. Deviation } & \multicolumn{2}{|c|}{ Std. Error Mean } \\
\hline & 19 & 7.89 & \multicolumn{2}{|c|}{0.32} & \multicolumn{2}{|c|}{0.07} \\
\hline \multirow{4}{*}{ One-Sample Test } & \multicolumn{6}{|c|}{ Test Value $=5$} \\
\hline & \multirow[t]{2}{*}{$\mathbf{t}$} & \multirow{2}{*}{ df } & \multirow{2}{*}{$\begin{array}{l}\text { Sig. }(2- \\
\text { tailed) }\end{array}$} & \multirow{2}{*}{$\begin{array}{c}\text { Mean } \\
\text { Difference }\end{array}$} & \multicolumn{2}{|c|}{$\begin{array}{l}\text { 95\% Confidence Interval of the } \\
\text { Difference }\end{array}$} \\
\hline & & & & & Lower & Upper \\
\hline & 40.02 & 18 & 0 & 2.90 & 2.74 & 3.05 \\
\hline
\end{tabular}

Source: Authors

The value for the warranty probability $p$ is less than $0.05(p=0.01)$. There is a difference between the arithmetic mean 2.90 and the control number $5 . \mathrm{H}_{0}$ can be rejected and the alternative $\mathrm{H}_{1}$ accepted. There is a statistically significant difference between the "input" and the final measurement. The observed effect size is $\mathrm{d}=9.17$ which is greater then |1.00|. According to Cohen (1988) it shows much larger magnitude than the magnitude of the influence of a typical intervention scheme on the riding dependency of the children studied. The systemic adjustment to hold and maintain a proper riding position, the continued encouragement during treatment sessions gave excellent results - the children gradually mastered skills for proper bodywork, which catalyzed a sense of stability and security. It is assumed that this provokes a strong motivation for autonomy and self-dependence (Henn, 2003). 
From Table 3 the final results of the Bertotti test for posture assessment during the ride can be tracked.

\begin{tabular}{|c|c|c|c|c|c|c|}
\hline \multirow{2}{*}{$\begin{array}{l}\text { One-Sample } \\
\text { Statistics }\end{array}$} & $\mathbf{N}$ & Mean & \multicolumn{2}{|c|}{ Std. Deviation } & \multicolumn{2}{|c|}{ Std. Error Mean } \\
\hline & 19 & 14.47 & \multicolumn{2}{|c|}{0.73} & \multicolumn{2}{|c|}{0.17} \\
\hline \multirow{4}{*}{ One-Sample Test } & \multicolumn{6}{|c|}{ Test Value $=11$} \\
\hline & \multirow[t]{2}{*}{$\mathbf{t}$} & \multirow[t]{2}{*}{ df } & \multirow{2}{*}{$\begin{array}{l}\text { Sig. }(2- \\
\text { tailed) }\end{array}$} & \multirow{2}{*}{$\begin{array}{c}\text { Mean } \\
\text { Difference }\end{array}$} & \multicolumn{2}{|c|}{$\begin{array}{l}\text { 95\% Confidence Interval of the } \\
\text { Difference }\end{array}$} \\
\hline & & & & & Lower & Upper \\
\hline & 22.21 & 18 & 0 & 3.74 & 3.38 & 4.09 \\
\hline
\end{tabular}

Source: Authors

The value obtained for the warranty probability $p$ is less than $0.05(p=0.01)$. This gives a reason to conclude that there is a difference between the arithmetic mean $\bar{x}=3.74$ and the control number $11 . \mathrm{H}_{0}$ is rejected and the alternative $\mathrm{H}_{1}$ is accepted, which is evidence of a statistically significant difference between the "input" and the last measurement. The magnitude of the effect $(d=4.73>|1.00|)$ according to Cohen (1988) is interpreted as much greater than the typical magnitude of the effect of the applied system on the position of the examined children during riding.

The comparative approach to the Bertotti test results shows the achievement of remarkable progress in posture development during riding. The children have improved the position of their head and straightened their torso - a positive consequence of the manual correction by the therapists and the conditions created for keeping them in an upright position on the back of the horse during riding. All muscle groups have been mobilized throughout the body. The smooth and rhythmic vibrations carried by the pelvis during the horse's drive have improved its stability and steadiness.

The aim of the study was to investigate the effects of hippotherapy as an alternative method for improving the praxis function of children with multiple disabilities. The primary results obtained from this study show that the intervention was effective to improve the equilibrium resistance of the experimental participants. Proof of this is the magnitude of the effect $(0.97>|0.80|)$. The findings of the favorable effect of horseback riding on the mentioned pattern correspond to other literature studies suggesting that the effects after practice of hippotherapy included improvement in balance and increased range of motion (Quint et al., 1998; Kuczynski \& Slonka, 1999). In terms of the structured therapeutic program, the results confirmed the importance of organizing and conducting therapeutic sessions for the development of balance stability. Equilibrium is one of the first habits used by the child in the process of mastering the control of one's own body.

The results of the horseback riding dependency test reproduce the established trend from the first test. The statistically significant difference in values in both measurements indicated the positive effect of therapeutic procedures on the investigated parameter. The magnitude of the effect $(9.17>|1.00|)$ in Cohen (1988) is a good attestation to reduce the degree of dependency to the therapist after the 5month training period. Mastering skills for self-control of the horse provides the possibility of switching from a feeling of dependence to a new sense - one of a person who can control a large animal, guiding him to the intended direction. In this context, there are relevant studies of children with cerebral palsy discussing the subjective improvements that may result from hippotherapy, including increased willingness and motivation to perform motor activities and improved selfperception and confidence (McGibbons et al., 1998; Casady et al., 2004).

Higher values were also recorded in the Bertotti test for posture assessment during horseback riding. The results of the present study, whose goal was to evaluate posture before and after hippotherapy, indicated favorable changes in postural alignment $(\mathrm{d}=4.73>|1.00|)$. A study that evaluated the trunk alignment in the sitting position, using hippotherapy as a treatment, showed symmetry in the pelvis weight transfer, further dissociation of pelvic girdle and cervical alignment (Alves et al., 2003). Another investigation reports that the sensorimotor stimuli applied to the individual sitting on the horse generate greater muscle activation of the extensor muscle groups of the spine and muscle tone normalization for triggering biomechanical adjustments, facilitating postural control (Debuse et al., 2005). This data corroborates our findings, which demonstrated that the stimuli provided by hippotherapy contribute to a better alignment of biomechanical structures. 


\section{Conclusion}

The obtained results show that hippotherapy is a complex therapeutic method that is suitable for improving the praxis function in children with multiple disorders. The following parameters were altered during the study: equilibrium resistance, correct body position, head position and torso straightening. According to the results of this study, horse therapy can be used as an alternative method for these children and may represent a form of rehabilitation in cases when other methods are less successful. The experimental research is important for the future of children with multiple disorders and their parents and therapists who put forward extreme efforts to improve the motoring potential of children. Compiling an individual program and strictly controlling the quality of the sessions is absolutely necessary for the effects of hippotherapy. It can be a reliable alternative method to help all parties involved in this process.

\section{References}

Alves, CN., Pettenuzzo, TSA., Klimiuk, BR., Santos, RV.(2003). Equoterapia e o alinhamento do tronco na postura sentada do paralisado cerebral. Revista Equoterapia. 7:5-10.

Casady R., Nichols-Larsen, D. (2004). The effect of hippotherapy on ten children with cerebral palsy. Ped Phys Ther. 16 (3): 165-172.

Cohen,, J. (1988). Statistical power analysis for the behavioral sciences. Lawrence Erlbaum Associates.

Debuse, D., Gibb, C., Chandler, C. (2005). An exploration of German and British physiotherapists' views on the effects of hippotherapy and their measurement. Physiother Theory Pract. 21 (4): 219-42.

Gencheva, N., Ivanova, I., Stefanova, D. (2015). Evaluation of Hippotherapy in the course of multiple sclerosis treatment, Activities in Physical Education and Sport, Vol. 5, No. 2, pp. 183-187.

Henn, H. (2003). A horse in therapy, hippotherapy and therapeutic pedagogy. M: MKKI publishing house, $376 \mathrm{pp.}$

Kuczynski, M, Slonka, K. (1999). Influence of artificial saddle riding on postural stability in children with CP. Gait Posture., 10 (2): $154-60$.

McCloskey, S. (2000). The effects of hippotherapy on gait in children with neuromuscular disorders. AHA News Summer pp.10-14.

McGibbons, NH., Andrade CK., Widener, G., Cintas, HL. (1998). Effect of an equine-movement therapy program on gait, energy expenditure, and motor function in children with cerebral palsy: a pilot study. Dev Med Child Neurol. 40:754-762.

Quint, C., Toomey, M. (1998). Powered Saddle and Pelvic Mobility: An investigation into the effects on pelvic mobility of children with cerebral palsy of a powered saddle which imitates the movements of a walking horse. Physiotherapy. 84(8): 376-84.

Scott, N. (2005). Special Needs, Special Horses: A Guide to the Benefits of Therapeutic Riding. Denton: University of North Texas Press.

Silkwood-Sherer, D., \& Warmbier, H. (2007). Effects of hippotherapy on postural stability in persons with multiple sclerosis: a pilot study. Journal of Neurologic Physical Therapy, 31(2), 77-84.

Snider, L., Korner-Bitensky, N., Kammann, C., Warner, S., \& Saleh, M. (2007). Horseback riding as therapy for children with cerebral palsy: Is there evidence of its effectiveness? Physical and Occupational Therapy in Pediatrics, 27, 5-23.

Vygotsky, L. S. (1998). Child psychology. New York: Plenum Press.

Whalen, C. N., \& Case-Smith, J. (2012). Therapeutic effects of horseback riding therapy on gross motor function in children with cerebral palsy: A systematic review. Physical and Occupational Therapy in Pediatrics, 32, 229-242. 